Universidad de Guadalajara

DERECHO GLOBAL. ESTUDIOS SOBRE DERECHO Y JUSTICIA Año 2021, Vol. VI. Número 18, Julio-Octubre, ISSN: 2448-5128 e-ISSN: 2448-5136

https://DOI.org/10.32870/dgedj.v6i18.352

CARLOS ORTEGA LAUREL Universidad Metropolitana, MeXico c.ortega@correo.ler.uam.mx

\title{
EL NOMBRE. DERECHO HUMANO RELACIONADO AL INTERÉS SUPERIOR DE LOS INFANTES
}

\author{
THE NAME. AS A HUMAN RIGHT RELATED TO \\ THE HIGHEST INTEREST OF INFANTS
}

Cómo citar el artículo:

Ortega C, (2021). El Nombre. Derecho Humano relacionado al Interés Superior de los Infantes. Derecho Global, Estudios sobre Derecho y Justicia, VI (18) Falta la paginación https://DOI. org/10.32870/dgedj.v6i18.352 pp. 103-125

Recibido: 24/04/2020 Aceptado: 20/09/2020 


\title{
RESUMEN
}

El nombre tiene una doble naturaleza jurídica, está claramente reconocido como un atributo de la personalidad (perspectiva civilista) y como un derecho humano. Sin embargo, aun cuando se trata de un derecho de las personas, la elección de éste siempre es una potestad de terceras personas (por regla general los progenitores). Lamentablemente este derecho hacía los padres o tutores goza de una libertad excesiva, que en muchas ocasiones ha sido dañina hacía la dignidad de los infantes. Es por ello por lo que se sugieren algunos marcos que delimiten la libertad de elección del nombre en aras del interés superior del menor. Se hace alusión a la más reciente reforma al Código Civil de la Ciudad de México.

\section{Palabras clave}

derecho humano, nombre, dignidad, libertad, interés superior del menor.

\begin{abstract}
The name has a double legal nature, it is clearly recognized as an attribute of the personality (civil perspective) and as a human right. However, even when it is a people right, the choice of it is always a third parties' power (usually the parents). Unfortunately, this right to parents or guardians enjoys excessive freedom, which on many occasions has been harmful to the infant's dignity. That is why some frameworks are suggested that delimit the name choice freedom for the sake of the best interests of the child. Allusion is made to the most recent reform to the Civil Code of Mexico City.
\end{abstract}

\section{KEYWORDS}

human right, name, dignity, freedom, superior younger interest.

\section{DERECHO GLOBAL. ESTUDIOS SOBRE DERECHO Y JUSTICIA}


Sumario: I. Introducción. II. Aspectos Jurídicos del Nombre en México. 1. Definición de Nombre. 2. El Nombre como atributo de la Personalidad. 3. El Nombre como Derecho Humano. 4. Criterios Jurisprudenciales sobre el Derecho Humano al Nombre y el Interés Superior del Menor. 4.1. Criterios Jurisprudenciales sobre el Derecho Humano al Nombre. 4.2. Criterios Jurisprudenciales sobre el Interés Superior del Menor. 5. Régimen Legal del Nombre en México. III. Restricción a la Libertad de elección del Nombre como protección de los menores. IV. Propuesta de Deberes a seguir por el Registro Civil para garantizar que el Nombre sea respetuoso de la Dignidad de la persona. V. Conclusiones. Bibliografía.

\section{INTRODUCCIÓN}

El nombre es un derecho humano, que está reconocido tanto en la Constitución Política de los Estados Unidos Mexicanos (artículo 29), como en la Convención Americana de los Derechos Humanos (artículo 18); asimismo la Suprema Corte de Justicia de la Nación (de México) ha emitido diversas jurisprudencias para delimitar el alcance del derecho humano al nombre; sin embargo, tanto la jurisprudencia, como la doctrina en general se han abocado al tema relativo a que toda persona tiene derecho a un nombre, pero se ha omitido aludir a los aspectos relativos a la identificación o en su caso rechazo hacía el nombre, por ser (éste) denigrante hacía la persona; en algunas entidades federativas, como el Estado de México, se han dado esbozos para legislar al respecto, además de existir, al menos, un par de países (Argentina y Rumania), en los que sea buscado prohibir que los menores sean registrados con nombres que les puedan generar una afectación en su autoestima o que sean objeto de burla.

En este artículo se busca indicar que el derecho humano al nombre debe manifestarse desde el momento en que es elegido el nombre de la persona, y que éste (el nombre) debe ser respetuoso de la identidad de la persona. En muchos países, incluido México, no se respeta el género de las personas y su relación con el nombre, de tal modo que tenemos hombres a los cuales sus padres les pusieron 
nombres que se asocian con el género femenino, por ejemplo; Guadalupe, María, Rosario, Concepción; lo mismo pasa en relación con las mujeres, así hay mujeres que se les nombró: José, Gabriel, Jesús, Rafael, etcétera; y ni que mencionar de la larga lista de "nombres" que suenan a broma, pero que lamentablemente han sido la carga que muchas personas han llevado en su vida: Masiosare, Aniv de la Rev, Batman, Increíble, Herculano, Petronila, Pancracia, Anacleto, Marciano, Filomena, Zenén, Domitila, en fin, la lista es indeterminable y no es el caso hacer una muestrario de "nombres" que mueven a risa, pero que, sin duda, han sido motivo de sufrimiento para las personas que los llevan.

Concluimos justificando las razones por las cuales se debe legislar indicando el deber del Registro Civil al registrar una persona, de constatar que el nombre sea acorde con su género y que sea respetuoso de su integridad como individuo, señalando una prueba de registro que limite la posibilidad de que el nombre elegido impacte negativamente en su integridad como persona.

El texto es desarrollado con base en una metodología analítica-juídica, en principio son acotados los conceptos claves, se les da un alcance jurídico y posteriormente, se describe el problema a resolver, para finalmente concluir con las mínimas propuestas que deben ser tomadas como base para una solución efectiva del problema.

\section{Aspectos Jurídicos Del Nombre en México}

\section{Definición de Nombre}

El concepto de nombre es definido por la Real Academia Española como: "Del lat. nomen, -innis. 1. m. Palabra que designa o identifica seres animados o inanimados" (RAE, 2014).

A su vez distintos juristas proporcionan sus respectivas definiciones:

\section{DERECHO GLOBAL. ESTUDIOS SOBRE DERECHO Y JUSTICIA}


- Domínguez Martínez define al nombre como "el conjunto de vocablos, el primero opcional y los segundos por filiación, mediante los cuales una persona física es individualizada e identificada por el Estado y en sociedad" (Domínguez, 2006, p. 254).

- De Pina, lo conceptualiza indicando que "es el signo que distingue a una persona de las demás en sus relaciones jurídicas y sociales" (De Pina, 2000, p. 210).

- Lacavex, indica que puede tener dos acepciones. En sentido restringido se refiere únicamente al nombre propio y en un sentido amplio, se refiere al conjunto de vocablos formado por el nombre o nombres de pila y los apellidos" (Lacavex, 2002).

- Treviño, "se forma con uno o más nombres propios y los apellidos (patronímicos). Se compone del nombre propio ... y el nombre de familia, apellido o patronímico" (Treviño, 2002, p. 46).

\section{El Nombre como Atributo de la Personalidad}

Valencia, asertivamente refiere que el atributo de la personalidad por excelencia es el nombre "sirve para individualizar a las personas" (Valencia, 2010, p. 255). Prácticamente todos los grandes civilistas mexicanos reconocen en el nombre un atributo de la personalidad (De Pina, Domínguez Martínez, Gutiérrez y González, Magallón Ibarra, Rojina Villegas, Treviño García, por citar algunos).

Al ubicar al nombre como un atributo de la personalidad, circunscribimos nuestro objeto de estudio al campo del derecho civil; sin embargo, el hecho de que las teorías sobre los atributos de la personalidad se hayan desarrollado dentro del derecho común, no es óbice para negar que, los atributos de la personalidad tienen un régimen jurídico transversal a prácticamente todas las ramas del derecho; en el caso del nombre es incuestionable la vinculación con el derecho penal, con los derechos de autor, el derecho administrativo, el derecho mercantil, por mencionar los más evidentes. 
Domínguez indica:

"El nombre de una persona física sea uno de los atributos de la personalidad se traduce en primer lugar, en que todo ser humano tiene un nombre, el cual, en última instancia, se compone con el correspondiente apellido paterno de sus progenitores, por lo que cuenta con él desde el mismo momento de su procreación; se ve complementado con el número ordinal que le correspondiere como hijo de esa pareja, a reserva de que le sea asignado oficialmente un nombre de pila..." (Domínguez, 2006, p. 255).

\section{El Nombre como Derecho Humano}

Como bien se sabe el catálogo de los derechos humanos se ha ido ampliando generación tras generación, a partir de la Declaración de los Derechos del Hombre hasta las últimas declaratorias o propuestas doctrinarias en las que se incluyen más y más prerrogativas hacía los seres humanos; en ese tenor es que surge el derecho humano al nombre.

La Convención Americana sobre Derechos Humanos (Pacto de San José) realizada del 7 al 22 de noviembre de 1969, es posiblemente el primer instrumento internacional que reconoce el derecho humano al nombre:

Artículo 18: Toda persona tiene derecho a un nombre propio y a los apellidos de sus padres o al de uno de ellos. La ley reglamentará la forma de asegurar este derecho para todos, mediante nombres supuestos, si fuere necesario (Organización de los Estados Americanos,1969).

Actualmente la Constitución Política de los Estados Unidos Mexicanos (CPEUM) reconoce el derecho humano al nombre:

Artículo 29....En los decretos que se expidan, no podrá restringirse ni suspenderse el ejercicio de los derechos a la no discriminación, al reconocimiento de la personalidad jurídica, a la vida, a la integridad personal, a la protección a la familia, al nombre, a la nacionalidad; los derechos de la niñez; los derechos políticos; las libertades de pensamiento, conciencia y de

108 DERECHO GLOBAL. ESTUDIOS SOBRE DERECHO Y JUSTICIA 
El Nombre. Derecho Humano relacionado al intéres Superior de los Infantes

profesar creencia religiosa alguna; el principio de legalidad y retroactividad; la prohibición de la pena de muerte; la prohibición de la esclavitud y la servidumbre; la prohibición de la desaparición forzada y la tortura; ni las garantías judiciales indispensables para la protección de tales derechos. (Cámara de Diputados del H. Congreso de la Unión México, 2019)

\section{Criterios Jurisprudenciales sobre el Derecho Humano al Nombre y el Interés Superior del Menor}

\subsection{Criterios Jurisprudenciales sobre el Derecho Humano al Nombre}

La Suprema Corte de Justicia de la Nación (mexicana) ha emitido diversas jurisprudencias que tienen que ver con el derecho humano al nombre, aunque es pertinente aclarar que el sentido de las jurisprudencias ha sido el de dilucidar la constitucionalidad de legislaciones secundarias que prohibían la posibilidad de modificar el nombre.

DERECHO HUMANO AL NOMBRE. SU SENTIDO Y ALCANCE A PARTIR DE LA CONSTITUCIÓN POLÍTICA DE LOS ESTADOS UNIDOS MEXICANOS Y A LA LUZ DE LOS TRATADOS INTERNACIONALES. Conforme a las obligaciones establecidas en el artículo 1o. de la Constitución Política de los Estados Unidos Mexicanos, en relación con el numeral 29 del mismo ordenamiento, se advierte que el sentido y alcance del derecho humano al nombre, a partir de su propio contenido y a la luz de los compromisos internacionales contraídos por el Estado Mexicano en la materia, son el conjunto de signos que constituyen un elemento básico e indispensable de la identidad de cada persona sin el cual no puede ser reconocida por la sociedad; este derecho está integrado por el nombre propio y los apellidos; lo rige el principio de autonomía de la voluntad, pues debe elegirse libremente por la persona misma, los padres o tutores, según sea el momento del registro; y, por tanto, no puede existir algún tipo de restricción ilegal o ilegítima al derecho ni interferencia en la decisión; sin embargo, puede ser objeto de reglamentación estatal, siempre que ésta no lo prive de su contenido esencial; incluye dos dimensiones, la primera, relativa a tener un nombre y, la segunda, concerniente al ejercicio de modificar el dado originalmente por los padres al momento del registro, por lo que, una vez registrada la persona, debe garantizarse la posibilidad de preservar o modificar el nombre y apellido; y, es un derecho no suspendible, incluso en tiempos de excepción. Así, la regulación para el ejercicio del derecho al nombre es constitucional y convencionalmente válida siempre que esté en ley bajo condiciones 
dignas y justas, y no para establecer límites que en su aplicación equivalgan en la realidad a cancelar su contenido esencial.

Época: Décima Época. Registro: 2000213. Instancia: Primera Sala. Tipo de Tesis: Aislada. Fuente: Semanario Judicial de la Federación y su Gaceta. Libro V, Febrero de 2012, Tomo 1. Materia(s): Constitucional. Tesis: 1a. XXV/2012 (10a.). Página: 653. (Suprema Corte de Justicia de la Nación (SCJN), 2012)

DERECHO HUMANO AL NOMBRE. ES UN ELEMENTO DETERMINANTE DE LA IDENTIDAD. El derecho humano al nombre a que se refiere el artículo 29 de la Constitución Política de los Estados Unidos Mexicanos, tiene como fin fijar la identidad de una persona en las relaciones sociales y ante el Estado, de suerte que la hace distinguible en el entorno, es decir, es una derivación integral del derecho a la expresión de la individualidad, por cuanto es un signo distintivo del individuo ante los demás, con el cual se identifica y lo reconocen como distinto. Por tanto, si la identificación cumple con la función de ser el nexo social de la identidad, siendo uno de sus elementos determinantes el nombre, éste, al ser un derecho humano así reconocido es, además, inalienable e imprescriptible, con independencia de la manera en que se establezca en las legislaciones particulares de cada Estado.

Época: Décima Época. Registro: 2000343. Instancia: Primera Sala. Tipo de Tesis: Aislada. Fuente: Semanario Judicial de la Federación y su Gaceta. Libro VI, Marzo de 2012, Tomo 1. Materia(s): Constitucional. Tesis: 1a. XXXII/2012 (10a.). Página: 275. (SCJN, 2012).

\subsection{Criterios Jurisprudenciales sobre el Interés Superior del Menor}

El más alto tribunal mexicano también ha emitido diversas opiniones jurisprudenciales que orientan el sentido en que debe entenderse "el interés superior del menor", que si bien, están enfocados al campo jurisprudencial, también sirven como guía en relación con el tema que nos ocupa, destacado las siguientes tesis:

DERECHOS DE LAS NIÑAS, NIÑOS Y ADOLESCENTES. EL INTERÉS SUPERIOR DEL MENOR SE ERIGE COMO LA CONSIDERACIÓN PRIMORDIAL QUE DEBE DE ATENDERSE EN CUALQUIER DECISIÓN QUE LES AFECTE. El artículo 2, segundo párrafo, de la Ley General de los Derechos de Niñas, Niños y Adolescentes prevé que el “interés superior de la niñez deberá ser considerado de manera primordial en la toma de decisiones sobre una cuestión debatida que involucre niñas, niños y adolescentes"; de ahí que cuando se 
tome una decisión que les afecte en lo individual o colectivo, "se deberán evaluar y ponderar las posibles repercusiones a fin de salvaguardar su interés superior y sus garantías procesales". $\mathrm{Al}$ respecto, debe destacarse que el interés superior del menor es un concepto triple, al ser: (I) un derecho sustantivo; (II) un principio jurídico interpretativo fundamental; y (III) una norma de procedimiento. El derecho del interés superior del menor prescribe que se observe "en todas las decisiones y medidas relacionadas con el niño", lo que significa que, en "cualquier medida que tenga que ver con uno o varios niños, su interés superior deberá ser una consideración primordial a que se atenderá", lo cual incluye no sólo las decisiones, sino también todos los actos, conductas, propuestas, servicios, procedimientos y demás iniciativas. Así, las decisiones particulares adoptadas por las autoridades administrativas -en esferas relativas a la educación, el cuidado, la salud, el medio ambiente, las condiciones de vida, la protección, el asilo, la inmigración y el acceso a la nacionalidad, entre otras- deben evaluarse en función del interés superior del niño y han de estar guiadas por él, al igual que todas las medidas de aplicación, ya que la consideración del interés superior del niño como algo primordial requiere tomar conciencia de la importancia de sus intereses en todas las medidas y tener la voluntad de dar prioridad a esos intereses en todas las circunstancias, pero sobre todo cuando las medidas tengan efectos indiscutibles en los niños de que se trate.

Época: Décima Época. Registro: 2013385. Instancia: Segunda Sala. Tipo de Tesis: Aislada. Fuente: Gaceta del Semanario Judicial de la Federación. Libro 38, Enero de 2017, Tomo I. Materia(s): Constitucional. Tesis: 2a. CXLI/2016 (10a.). Página: 792. (SCJN, 2017).

\section{INTERÉS SUPERIOR DEL MENOR. DIMENSIONES EN QUE SE PROYECTA LA APLICACIÓN DE ESTE PRINCIPIO.}

De la jurisprudencia 1a./J. 44/2014 (10a.), de esta Primera Sala de la Suprema Corte de Justicia de la Nación, de título y subtítulo: "INTERÉS SUPERIOR DEL MENOR. SU CONFIGURACIÓN COMO CONCEPTO JURÍDICO INDETERMINADO Y CRITERIOS PARA SU APLICACIÓN A CASOS CONCRETOS.” (1), deriva que el interés superior del menor es un principio vinculante dentro de nuestro ordenamiento jurídico, cuya aplicación se proyecta en tres dimensiones: a) como derecho sustantivo, en cuanto a que el interés referido sea consideración primordial y se tenga en cuenta al sopesar distintos intereses respecto a una cuestión debatida; b) como principio jurídico interpretativo fundamental, en el sentido de que si una norma jurídica admite más de una interpretación, se elegirá la que satisfaga de forma más efectiva sus derechos y libertades, a la luz del interés superior del menor; y, c) como norma de procedimiento, conforme a la cual, siempre que se tome una decisión que afecte los intereses de uno o más menores de edad, deberá incluirse en el proceso de decisión, una estimación de las posibles repercusiones en ellos. Asimismo, la 
justificación de la medida adoptada deberá dejar patente que se consideró el interés superior del menor en el análisis de las diversas alternativas posibles.

Época: Décima Época. Registro: 2010602. Instancia: Primera Sala. Tipo de Tesis: Aislada. Fuente: Gaceta del Semanario Judicial de la Federación. Libro 25, Diciembre de 2015, Tomo I. Materia(s): Constitucional. Tesis: 1a. CCCLXXIX/2015 (10a.). Página: 256. (SCJN, 2015).

INTERÉS SUPERIOR DEL MENOR. SU CONFIGURACIÓN COMO CONCEPTO JURÍDICO INDETERMINADO Y CRITERIOS PARA SU APLICACIÓN A CASOS CONCRETOS. Resulta ya un lugar común señalar que la configuración del interés superior del menor, como concepto jurídico indeterminado, dificulta notablemente su aplicación. Así, a juicio de esta Primera Sala, es necesario encontrar criterios para averiguar, racionalmente, en qué consiste el interés del menor y paralelamente determinarlo en concreto en los casos correspondientes. Es posible señalar que todo concepto indeterminado cabe estructurarlo en varias zonas. Una primera zona de certeza positiva, que contiene el presupuesto necesario o la condición inicial mínima. Una segunda zona de certeza negativa, a partir de la cual nos hallamos fuera del concepto indeterminado. En tercer y último lugar la denominada zona intermedia, más amplia por su ambigüedad e incertidumbre, donde cabe tomar varias decisiones. En la zona intermedia, para determinar cuál es el interés del menor y obtener un juicio de valor, es necesario precisar los hechos y las circunstancias que lo envuelven. En esta zona podemos observar cómo el interés del menor no es siempre el mismo, ni siquiera con carácter general para todos los hijos, pues éste varía en función de las circunstancias personales y familiares. Además, dicha zona se amplía cuando pasamos -en la indeterminación del concepto- del plano jurídico al cultural. Por lo anterior, es claro que el derecho positivo no puede precisar con exactitud los límites del interés superior del menor para cada supuesto de hecho planteado. Son los tribunales quienes han de determinarlo moviéndose en esa "zona intermedia", haciendo uso de valores o criterios racionales. En este sentido, es posible señalar como criterios relevantes para la determinación en concreto del interés del menor en todos aquellos casos en que esté de por medio la situación familiar de un menor, los siguientes: a) se deben satisfacer, por el medio más idóneo, las necesidades materiales básicas o vitales del menor, y las de tipo espiritual, afectivas y educacionales; b) se deberá atender a los deseos, sentimientos y opiniones del menor, siempre que sean compatibles con lo anterior e interpretados de acuerdo con su personal madurez o discernimiento; y c) se debe mantener, si es posible, el statu quo material y espiritual del menor y atender a la incidencia que toda alteración del mismo pueda tener en su personalidad y para su futuro. Asimismo, es necesario advertir que para valorar el interés del menor, muchas veces se impone un estudio comparativo y en ocasiones beligerante entre varios intereses en conflicto, por lo que el juez tendrá que examinar las circunstancias específicas de cada caso para poder llegar a una solución estable, justa y equitativa especialmente para el menor, cuyos intereses 
deben primar frente a los demás que puedan entrar en juego, procurando la concordancia e interpretación de las normas jurídicas en la línea de favorecer al menor, principio consagrado en el artículo 4o. constitucional.

Época: Décima Época. Registro: 2006593. Instancia: Primera Sala. Tipo de Tesis: Jurisprudencia. Fuente: Gaceta del Semanario Judicial de la Federación. Libro 7, Junio de 2014, Tomo I. Materia(s): Constitucional. Tesis: 1a./J. 44/2014 (10a.). Página: 270. (SCJN, 2014).

\section{Régimen Legal del Nombre en México}

Como ya se mencionó en el apartado 1.3, la CPEUM reconoce expresamente el derecho humano al nombre en su artículo 29 y con ello sienta la base constitucional para el régimen legal del nombre.

El nombre al ser un atributo de la personalidad, como ya se ensayó, está integrado al derecho civil, y siendo la materia civil competencia del fuero local, corresponde a cada entidad federativa legislar al respecto; no obstante ello, el Código Civil Federal también regula cuestiones relativas al nombre. Lo anterior es así, por disponerlo el artículo 124 de la Constitución Política de los Estados Unidos Mexicanos, mismo que indica lo siguiente: "Las facultades que no están expresamente concedidas por esta Constitución a los funcionarios federales, se entienden reservadas a los Estados o a la Ciudad de México, en los ámbitos de sus respectivas competencias." Como puede colegirse de lo anterior, si dentro de las facultades que dicha Constitución otorga a las autoridades federales, está la de regular las relaciones civiles, pues se trataría de una atribución federal, en caso contrario, le corresponde al ámbito estatal, que es lo que acontece.

Las treinta y dos entidades federativas mexicanas, ya sea en sus códigos civiles o familiares (y una ley del Registro Civil), norman aspectos relativos al nombre; existen marcadas diferencias entre la manera en que está legislado el nombre, de una entidad a otra, pero a pesar de ello, no se encuentran incompatibilidades normativas que den base a una antinomia. 
En términos generales la regulación legal referente al nombre está estrechamente vinculada al registro de las personas, al actuar del titular de la oficina registral civil, a la composición del nombre y, en algunos Estados, a la modificación del nombre.

Además de la legislación civil respecto al nombre, también se tienen disposiciones penales del fuero común en relación con el nombre; prácticamente en todos los Estados de la República Mexicana se tienen disposiciones que contemplan algún tipo penal con necesaria vinculación al nombre; el Código Penal del Distrito Federal, lo regula en los términos siguientes:

ARTÍCULO 317. Se impondrá de seis meses a dos años prisión o de noventa a ciento cincuenta días de trabajo en favor de la comunidad, al que ante una autoridad judicial o administrativa en ejercicio de sus funciones, oculte o niegue su nombre o apellido o se atribuya uno distinto del verdadero, u oculte o niegue su domicilio o designe como tal uno distinto del verdadero.

Son de destacarse, por relacionarse a nuestra materia de estudio, las disposiciones legales de los siguientes Estados:

\section{CÓDIGO CIVIL DE CHIHUAHUA}

ARTÍCULO 60. El nombre está constituido por el nombre propio, primero y segundo apellidos.

Para la asignación del nombre propio, se observará lo siguiente:

I. No podrá integrarse por más de dos sustantivos;

II. No se constituirá con palabras denigrantes de la personalidad;

III. No se emplearán apodos; y

IV. No podrá constituirse con números. 
Los apellidos corresponderán por su orden, el primero del padre y al primero de la madre. (Heroico Congreso del Estado de Chihuahua, 2017)

\section{CÓDIGO CIVIL PARA EL DISTRITO FEDERAL (CIUDAD DE MÉXICO)}

GACETA OFICIAL DE LA CIUDAD DE MÉXICO. 24 de octubre de 2017.

\section{DECRETO POR EL QUE SE REFORMAN DIVERSAS DISPOSICIONES DEL CÓDIGO CIVIL PARA EL DISTRITO FEDERAL}

ARTÍCULO ÚNICO. - Se adiciona un párrafo y se reforman los párrafos primero y último del artículo 58 del Código Civil para el Distrito Federal, para quedar como sigue:

Artículo 58.- El acta de nacimiento contendrá el día, la hora y el lugar del nacimiento, el sexo del presentado, el nombre o nombres propios y los apellidos de los progenitores en el orden de prelación que ellos convengan, el Juez del Registro Civil deberá especificar, de forma expresa, el orden que acuerden. el orden de los apellidos acordado se considerará para los demás hijos e hijas del mismo vínculo, asimismo, en su caso, la razón de si el registrado se ha presentado vivo o muerto y la impresión digital del mismo. Si se desconoce el nombre de los padres, el Juez del Registro Civil le pondrá el nombre y apellidos, haciendo constar esta circunstancia en el acta.

Cuando no haya acuerdo entre los progenitores, el juez dispondrá el orden de los apellidos.

El Juez del Registro Civil, exhortará a quien presente al menor que el nombre propio con el que se pretende registrar no sea peyorativo, discriminatorio, infamante, denigrante, carente de significado, o que constituya un signo, símbolo o siglas, o bien que exponga al registrado a ser objeto de burla.

En el caso del artículo 60 de este Código, el Juez del Registro Civil pondrá el primer apellido de los progenitores de acuerdo con el orden de prelación que ellos convengan o los dos apellidos del que lo reconozca.

Es pertinente acotar, que esta reforma tuvo por objeto eliminar la inequidad de género en lo relativo al orden los apellidos - hasta antes de esa reforma, el orden era el siguiente: primero el apellido paterno y luego el materno-; con la reforma, 
como se aprecia, ahora libremente los progenitores pueden elegir el orden de los apellidos, excepto cuando no se pongan de acuerdo, sin embargo, al dejar en el libre arbitrio del Juez (a cuál juez se referirá la norma: ¿Juez del Registro Civil o Juez de lo Familiar?) la solución de la falta de acuerdo, sigue subyacente el problema. Respecto a este tema (la inequidad de género derivada del orden imperante de los apellidos en la descendencia), uno de los suscritos tiene un par de trabajos publicados: "Agenda Pendiente en la Política Nacional de Equidad de Género y Derechos Humanos de la Mujer: Modificación al régimen jurídico del sistema de filiación parental-infantil en México" (Simental, 2015), e Inconstitucionalidad del apellido paterno en la integración del nombre (Simental, 2016, p. 33-35).

\section{LEY DEL REGISTRO CIVIL PARA EL ESTADO DE SONORA}

Artículo 46.- El oficial del registro civil orientará a quien comparezca a registrar a una persona, sobre la importancia en la selección del nombre propio, con el objeto de que el mismo, contribuya adecuadamente en el proceso del menor para forjarse una identidad. La Dirección General podrá realizar campañas de concientización entre la población, a efecto de reforzar lo dispuesto en el párrafo anterior. (Heroico Congreso del Estado de Sonora, 2018).

\section{CÓDIGO CIVIL DEL ESTADO DE QUERÉTARO}

Artículo 35. El nombre es el vocativo con el cual se designa a una persona y se compondrá del nombre propio y los apellidos, cuando se trate de personas físicas

Artículo 36. El nombre propio podrá constar de uno o varios vocativos, con los que se designe individualmente a una persona. Desde luego, en el caso de las personas físicas, se indicará por quienes los presenten ante el Oficial del Registro Civil, quién cuidará que no se contengan frases o palabras ininteligibles o que pudieran producir futura mofa o desprecio.

Los apellidos son los vocativos con los cuales se designa a todos y cada uno de los miembros de una familia. El uso de los apellidos se adquiere por filiación del padre y la madre o, en su caso, del que hubiere reconocido al hijo. En su defecto, se adquiere por resolución de autoridad judicial. (Poder Legislativo del Estado de Querétaro, 2019).

\section{DERECHO GLOBAL. ESTUDIOS SOBRE DERECHO Y JUSTICIA}




\section{RESTRICCión A La LibERTAD DE ELECCIÓN DEL NOM- BRe COMO Protección de los Menores}

Anaya Huerta, escribió un artículo en la revista Nexos en el que señala: como se han dado pasos en algunos países para limitar la libertad de los padres a seleccionar el nombre de los hijos, en ocasiones mediante facultades jurisdiccionales (E.U.), o en otros mediante disposición legal (Rumanía), "En octubre de 2011 entró en vigor en Rumania un nuevo Código Civil, cuyo artículo 84, fracción 2 prohíbe a los funcionarios civiles del Estado nombres indecentes, ridículos y otros que afecten al orden público, las buenas costumbres o los intereses del niño" (Anaya, 2013, p.23).

A simple vista puede parecer un tema sencillo (limitar el derecho de los padres para elegir el nombre de sus hijos), el problema estriba en que la disputa (de inicio) no se da entre padres que eligen un nombre feo para su hijo, y éste para defender su derecho a llevar un nombre que le agrade, sino entre los padres y el Estado, esa es la esencia del conflicto (por cierto, metajurídico).

Casella y Toia, atinadamente definen la problemática, en los términos siguientes:

En la cuestión existen dos órdenes de intereses a considerar. Uno, el social, relativo al registro por parte del Estado de las personas naturales como medio para su identificación social-interés público-; y otro, cuya proyección va más allá del mero dato formal y se refiere a la persona considerada tanto de modo individual como social -interés humano particular- (Casella y Toia, 2013, p. 307).

Los mismos autores señalan que la anterior premisa plantea la interrogante de que si el nombre es antes que un derecho un deber o a la inversa, ya que dependiendo de la elección serán distintos los efectos jurídicos resultantes.

El Decreto Ley 18.248, en su artículo $1^{\circ}$ dispone que: "Toda persona natural tiene el derecho y el deber de usar el nombre y apellido que le corresponde de acuerdo con las disposiciones de la presente ley". 
De interpretar que el nombre es un deber antes que un derecho, entonces la facultad reglamentaria del Estado sería el principio, y la libertad de los individuos la excepción, colocando -de ese modo- el orden social por sobre la libertad individual. Así se invierte el principio de libertad de acción establecido en el artículo 19 de la C.N. (Constitución Nacional de Argentina) (Casella y Toia, 2013, p. 308).

Sin embargo, en realidad el derecho humano al nombre, dado el momento en que es electo, se vincula más con los derechos del niño, es oportuno traer a colación lo que dispone la Convención sobre los Derechos del Niño en su artículo 8, el cual indica:

Artículo 8: 1. Los Estados Partes se comprometen a respetar el derecho del niño a preservar su identidad, incluidos la nacionalidad, el nombre y las relaciones familiares de conformidad con la ley sin injerencias ilícitas. (Asamblea General de las Naciones Unidas, 2006).

Al anterior artículo hay que vincularle de manera estrecha lo dispuesto por el Artículo 3, que a la letra indica:

Artículo 3: 1. En todas las medidas concernientes a los niños que tomen las instituciones públicas o privadas de bienestar social, los tribunales, las autoridades administrativas o los órganos legislativos, una consideración primordial a que se atenderá será el interés superior del niño. (Asamblea General de las Naciones Unidas, 2006).

Está relación se da, por la disposición de atender prioritariamente el interés superior del menor. Es evidente que el nombre tendrá un efecto trascendente en la vida de la persona por el resto de su existencia.

Por lo anterior, el Estado no puede permanecer inerte ante la "libertad" de los padres para elegir el nombre de los hijos, cuando la elección que estos hagan pueda ser contraria al interés superior del menor; en Argentina la ley si bien fijo como regla general la libertad de los padres para elegir el nombre de los hijos, "establece ciertas excepciones de importancia, ... entre ellas: 
1.- Nombres extravagantes, ridículas, contrarios a nuestras costumbres, que expresen tendencias políticas o ideológicas, o induzcan a la confusión del sexo; 2.- nombres extranjeros salvo que se encuentren castellanizados, o sean los nombres de los padres -si fuese de fácil pronunciación y no tuvieren traducción-; 3.- apellidos como nombres; 4.- primeros nombres idénticos a los de hermanos vivos; 5.- más de tres nombres" (Casella y Toia, 2013, p. 309).

Las disposiciones legales argentinas, han sido polémicas y han llevado a litigio la impugnación de éstas, especialmente lo relativo a la elección de nombres extranjeros. No es objeto de nuestro trabajo la racionalidad, justicia y o validez de las disposiciones argentinas, pero sirve como punto de referencia para nuestro estudio, ya que supera la legislación mexicana, que en el mejor de los casos (Chihuahua), prohíbe que los nombres se constituyan con palabras denigrantes de la personalidad, ni que se empleen apodos, pero omite señalar criterios que orienten al registrador para evitar el uso de nombres denigrantes.

\section{Propuesta de deberes a seguir por el Registro Ci- VIL PARA GARANTIZAR QUE EL NOMBRE SEA RESPETUOSO DE LA Dignidad de la PERSONA}

Como conclusión de lo analizado, se propone que en cada una de las 32 entidades federativas que integran a la Federación Mexicana, se modifique el Reglamento que regula el actuar del Registro Civil, esto es así, porque es mucho más sencillo emitir una disposición reglamentaria, que modificar la ley, en la cual intervienen intereses de índole partidista, que retrasan o impiden el avance del orden jurídico.

Está modificación reglamentaria, solamente se enfocaría a proteger el interés superior de los niños en cuanto a que los nombres elegidos por sus padres no atenten contra su dignidad.

De tal manera que el oficial o juez del Registro Civil (dependiendo de la Entidad de la que se trate) no solamente sugerirá que los nombres escogidos sean estéticamente gratos, sino que además impedirá que se seleccionen nombres de género contrario al menor, nombres que hagan alusión a personajes históricos denostados. 
El titular de la oficina registral llenará un listado mediante el cual verificará que el nombre es acorde con el interés superior del menor, para lo cual se propone el siguiente cuadro:

\begin{tabular}{|l|l|l|}
\hline \multicolumn{1}{|c|}{ Criterio } & \multicolumn{1}{c|}{ Evaluación } \\
\cline { 2 - 3 } El nombre es acorde con el género del menor. & & \\
\hline El nombre es distinto de cualquier apodo conocido. & & \\
\hline $\begin{array}{l}\text { El nombre es ajeno a cualquier connotación física } \\
\text { discriminatoria. }\end{array}$ & & \\
\hline El nombre no corresponde a algún apellido. & & \\
\hline $\begin{array}{l}\text { Se eligen máximo tres nombres comunes. } \\
\text { El nombre no corresponde a algún concepto o idea extravagante, } \\
\text { por ejemplo: el nombre de un artista o de una marca comercial, } \\
\text { como John Lennon, Superior. }\end{array}$ & & \\
\hline $\begin{array}{l}\text { El nombre no corresponde a algún concepto o idea con una } \\
\text { connotación negativa, por ejemplo: droga, demonio, tiniebla. }\end{array}$ & & \\
\hline $\begin{array}{l}\text { El nombre no corresponde a algún animal, vegetal o acción que } \\
\text { sea denigrante para la persona o para la sociedad en general, por } \\
\text { ejemplo: hiena, mariguana, asesino. }\end{array}$ & & \\
\hline
\end{tabular}

Como se puede advertir, el listado en cuestión para que facilite el registro de la persona deberá hacerse tachando en todos los casos la opción de SI, un solo NO, daría pie a negar el registro.

La labor de los titulares de las oficinas del Registro Civil reviste una importancia mayúscula ya que se constituyen en quienes pueden orientar a las personas de bajo nivel educativo o cultural para que seleccionen un nombre que respete la 
integridad de sus hijos, por tanto, estos servidores públicos también deberán ser capacitados para tener los conocimientos mínimos necesarios a fin de cumplir satisfactoriamente con esta encomienda, que sólo para quienes han sufrido toda su vida con un nombre denigrante, se puede saber lo importante que es la correcta elección de los nombres de los hijos.

\section{Conclusiones}

El constructo "Derechos Humanos" está en permanente evolución, la esencia conceptual de estos: la dignidad humana, sigue sin que sea agotada axiológica, ontológica, ni epistemológicamente hablando, de tal modo que seguiremos conociendo más sobre el contenido y los alcances de los derechos humanos, y especialmente, sobre su reconocimiento y defensa ante los poderes públicos y fácticos.

Dentro el cúmulo de derechos humanos específicos está el del "nombre”. Y pues esto es evidente, cómo pensar en un humano que manifieste dignidad, sin que goce de un nombre que lo identifique individualmente y que además le permita (eventualmente), tener un vínculo con sus progenitores.

La forma en que se integra el nombre no es uniforme a nivel global, ni en términos históricos, sin embargo, en una amplia diversidad de naciones se ha seguido un modelo común: el nombre propio y los apellidos (que son heredados de la madre y el padre).

Así como se ha generalizado el modelo de que va en primer término el apellido paterno y posteriormente el materno, también está ampliamente reconocida la facultad para los ascendientes de elegir el nombre de sus hijos, lo cual parece algo sano, en general.

No obstante, lo indicado en el párrafo inmediato anterior, admite muchas excepciones, cuando por diversas razones, los padres eligen un nombre que puede ser denigrante para su hijo. 
Cuando se selecciona un nombre para el hijo que atente contra su dignidad, es cuando el derecho a elegir nombre debe limitarse por el derecho de los hijos a tener un nombre que no atente contra su decoro, y que, probablemente le cause una amplia diversidad de afectaciones en su vida futura.

Es por lo antes expuesto, que se considera pertinente, que el Estado incluya entre sus deberes, en la etapa del registro de los menores, que los funcionarios encargados de esta labor, verifiquen que el nombre es respetuoso del derecho humano al nombre, y que este derecho, no solamente conlleva el relativo a tener nombre, sino que éste sea acorde con la dignidad humana.

Por supuesto que quedan siempre alternativas para atender (resolver) el permanente problema del nombre (de sí le gusta o no al sujeto que lo tiene): tales como podrían ser que siendo mayor de edad pueda ser cambiado (hoy en día esto es factible), ya se por la vía judicial, cuando sólo deriva de una cuestión "estética", o cuando corresponde a un cambio por identidad de género (por la vía administrativa, siendo mayor de edad, o por la vía judicial, para los menores de edad). Y por supuesto que estos medios de corrección de nombre pueden ser perfectibles, pero como sea operan cuando "el daño" está hecho, lo cual no es impedimento para tener formular que coadyuven en la etapa inicial del fenómeno en cuestión (al registro del menor). 


\section{Bibliografía}

Alonso Regueira, E., (2013). La Convención Americana de Derechos Humanos y proyección en el Derecho Argentino. Buenos Aires, Argentina: La Ley.

Anaya Huertas, A., (2013). "Sobre el derecho a llamarse Mesías y otros disparates". Revista Nexos. Recuperado de: https://eljuegodelacorte. nexos.com. $\mathrm{mx} / \mathrm{p} \mathrm{p}=3208$

Asamblea General de las Naciones Unidas, (2006). Convención sobre los Derechos del Niño. Nueva York, Estados Unidos: Oficina del alto comisionado.

Asamblea Legislativa del Distrito Federal, (2018). Código Civil para el Distrito Federal. Ciudad de México, México: Consejería Jurídica y de Servicios Legales.

Asamblea Legislativa del Distrito Federal, (2018). Código Penal del Distrito Federal. Ciudad de México, México: Consejería Jurídica y de Servicios Legales.

Cámara de Diputados del H. Congreso de la Unión México, (2019). Constitución Politica de los Estados Unidos Mexicanos. Ciudad de México, México: Secretaría de Servicios Parlamentarios.

De Pina, R., (2000). Derecho Civil Mexicano. Ciudad de México, México: Porrúa.

Domínguez Martínez, J. A., (2006). Derecho Civil. Ciudad de México, México: Porrúa.

Heroico Congreso del Estado de Chihuahua, (2017). Código Civil de Chihuahua. Chihuahua, México: Secretaría de Asuntos Legislativos y Jurídicos.

Heroico Congreso del Estado de Sonora, (2018). Ley del Registro Civil para el Estado de Sonora. Sonora, México: Dirección General Jurídica. 
Lacavex Berumen, M. A., (2002). "El nombre de las personas físicas". Revista Jurídica, Poder Judicial del Estado de Aguascalientes, (24). Organización de los Estados Americanos, (1969). Convención Americana de los Derechos Humanos (Pacto de San José de Costa Rica). San José, Costa Rica: Secretaría de Asuntos Jurídicos.

Poder Legislativo del Estado de Querétaro, (2019). Código Civil del Estado de Querétaro. Querétaro, México: Dirección de Investigación y Estadística Legislativa.

Real Academia Española, (2014). Diccionario de la lengua española. 23. ${ }^{a}$ edición. Recuperado de http://dle.rae.es/

Simental Franco, V. A. (2015). “Agenda Pendiente en la Política Nacional de Equidad de Género y Derechos Humanos de la Mujer: Modificación al régimen jurídico del sistema de filiación parentalinfantil en México". Trabajos ganadores del Premio Nacional de Investigación "Derechos Humanos de las Mujeres y la Igualdad de Género”, edición especial del Centro de Estudios para el Adelanto de las Mujeres y la Equidad de Género de la Cámara de Diputados.

Simental Franco, V. A. (2016). "Inconstitucionalidad del apellido paterno en la integración del nombre". Foro jurídico, (159), pp. 33-35.

Suprema Corte de Justicia de la Nación de México, (2012a). Derecho humano al nombre. Su sentido y alcance a partir de la constitución política de los estados unidos mexicanos y a la luz de los tratados internacionales. Semanario Judicial de la Federación, décima época. Disponible en: https://www.buscatdh.bjdh.org.mx/ Jurisprudencia\%20Mexicana/2000213.pdf

Suprema Corte de Justicia de la Nación de México, (2012b). Derecho humano al nombre. Es un elemento determinante de la identidad. Semanario Judicial de la Federación, décima época. Disponible en: https://sjf.scjn.gob.mx/sjfsist/documentos/tesis/2000/2000343.pdf Suprema Corte de Justicia de la Nación de México, (2013). Interés superior del menor. Su configuración como concepto jurídico indeterminado 
y criterios para su aplicación a casos concretos. Semanario Judicial de la Federación, décima época. Disponible en: https://sjf.scjn.gob. $\mathrm{mx} / \mathrm{sjfsist/Documentos/Tesis/2002/2002815.pdf}$

Suprema Corte de Justicia de la Nación de México, (2015). Interés superior del menor. Dimensiones en que se proyecta la aplicación de este principio. Semanario Judicial de la Federación, décima época. Disponible en: https://sjf.scjn.gob.mx/sjfsist/Documentos/ Tesis/2010/2010602.pdf

Suprema Corte de Justicia de la Nación de México, (2017). Derechos de las niñas, niños y adolescentes. El interés superior del menor se erige como la consideración primordial que debe de atenderse en cualquier decisión que les afecte. Semanario Judicial de la Federación, décima época. Disponible en: https://sjf.scjn.gob.mx/sjfsist/Documentos/ Tesis/2013/2013385.pdf

Treviño García, R., (2002). La persona y sus atributos. Nuevo León, México: Universidad Autónoma de Nuevo León.

Valencia Mongue, J. G., (2012). Los atributos de la personalidad, Breve análisis de su aplicación en el Código Civil vigente. Conmemoración de los 80 años de vigencia del código civil, 255-275. Recuperado de: https://archivos.juridicas.unam.mx/www/bjv/libros/8/3833/18.pdf 
